\title{
EMERGING TRENDS IN STRATEGIC PLANNING
}

\author{
Fred R. David ${ }^{1}$, Forest R. David ${ }^{2}$, Tünde Zita Kovács ${ }^{3}$, András Nábrádii ${ }^{4}$ \\ ${ }^{1}$ Professor, Francis Marion University, USA, \\ ${ }^{2} \mathrm{PhD}$ Student University of Debrecen, Faculty of Economics and Business, \\ ${ }^{3} \mathrm{PhD}$ Student University of Debrecen, Faculty of Economics and Business, \\ ${ }^{4}$ Professor, University of Debrecen, Faculty of Economics and Business,
}

\author{
freddavid9@gmail.com \\ forestdavid5@gmail.com \\ kovacs.tunde.zita@econ.unideb.hu \\ nabradi.andras@econ.unideb.hu
}

\begin{abstract}
In today's rapidly changing world, there is an increased need for excellent strategic planning. A firm's survival may indeed hinge on the firm's planning process being exemplary. Various aspects of the strategic planning process are under review today as organizations wrestle to compete more effectively. This paper reveals and describes five emerging trends or tools being utilized today by firms to more effectively engage in strategic planning. Specifically, the emerging trends and tools to be discussed in this paper are as follows:

1) Assure vision and mission statements include desired characteristics

2) Perform SWOT (Strengths-Weaknesses-Opportunities-Threats) analysis using AQCD (Actionable, Quantitative, Comparative, and Divisional) factors

3) Utilize varied sources to obtain AQCD information

4) Utilize QSPM (Quantitative Strategic Planning Matrix) analysis to determine the relative attractiveness of alternative strategies

5) Use excel-based software to facilitate and enhance the strategic planning process.

The purpose of this paper is to familiarize readers with basic new tools and techniques being used by organizations to effectively develop an improved strategic plan for the firm.
\end{abstract}

Keywords: vision-mission, strategic planning, AQCD approach, QSPM analysis, strategic planning software.

(JEL Classification: $M 21, O 21$ )

\section{INTRODUCTION}

Every day companies and organizations make strategic decisions regarding what markets to enter, what markets to avoid, which competitors to acquire, and which firms and products to avoid. A firm's survival can hinge on these decisions being made correctly. Deciding what to produce and where, when, and how to compete is what leads to a sustainable competitive advantage. Even the best strategies must be implemented well through operational- or tacticallevel activities like hiring and motivating employees, cutting costs, benchmarking, outsourcing, securing financing, and keeping facilities warm (or cool). Implementation activities are vitally important and must be monitored by strategists. However, effective strategy formulation, more so than operational tactics, are generally what lead to sustained competitive advantage. Strategic planning also consist of a series of concepts and tools when combined can yield positive results (Bryson, et al., 2018). Accordingly, this paper aims to enhance the process that firms utilize to formulate and ultimately decide upon particular strategies to implement.

To gain a sustainable competitive advantage, firms need 
to provide unique products and services. Uniqueness matters. For example, Apple's computers, iPods, and iPhones all run on Apple's unique operating system. To assure necessary "uniqueness," firms must accept concessions in the strategy process to gain a sustainable competitive, as exemplified in the Apple example. All successful firms thus make trade-offs and tough decisions to establish uniqueness in developing, producing, and selling products and/or services.

This paper begins by discussing recent changes in how firms establish their vision and mission-items that represent the starting point for developing and nurturing a firm's uniqueness. Everything in strategy flows from a particular institution's vision and mission, and all successful firms are different (unique) from rival firms in some key ways.

A strategic plan is, in essence, a company's game plan. Profit margins among firms in most industries are so slim that there is little room for error in the overall strategic plan. A strategic plan results from tough managerial choices among numerous good alternatives, and it signals commitment to specific markets, policies, procedures, and operations in lieu of other, "less desirable" courses of action. Strategic planning is all about gaining and maintaining competitive advantage, and this paper aims to enhance this process. Normally, a firm can sustain a competitive advantage for only a certain period because of rival firms imitating and undermining that advantage. Thus, it is not adequate simply to obtain competitive advantage; firms must strive to achieve sustained competitive advantage by doing the following (David et al., 2020, p. 10):

1. Continually adapting to changes in external trends and events and internal capabilities, competencies, and resources.

2. Effectively formulating, implementing, and evaluating strategies that capitalize on those factors.

3. Offering products that are unique and not easily duplicated by rivals.

4. Accepting trade-offs by deciding what not to do; no firm can be everything to everybody.

This paper aims to reveal and describe five recent trends or tools that are enabling firms to gain competitive advantage over rival firms through engagement in more effective strategic planning. Specifically, the five new activities or practices being utilized are:

1) Assure vision and mission statements include desired characteristics

2) Perform SWOT (Strengths-Weaknesses-OpportunitiesThreats) analysis using AQCD (Actionable, Quantitative, Comparative, and Divisional) factors

3) Utilize varied sources to obtain AQCD information

4) Utilize QSPM (Quantitative Strategic Planning Matrix) analysis to determine the relative attractiveness of alternative strategies

5) Use excel-based software to facilitate and enhance the strategic planning process.

\section{Trend 1: assure vision and mission statements}

\section{include desired characteristics}

Vision and mission statements are not just words that look nice when framed or engraved; they provide a basis for strategy and action; they reveal the reason a business opens its doors every day, the reason salespersons sell, the reason customers buy, and the reason employees work. These statements ideally are the passion behind the company, the foundation for employee morale, and the basis for customer loyalty. Recently, organizations are devising these statements to incorporate new characteristics and components, as revealed in this paper. Clear vision and mission statements enable strategists to lead the way as a firm strives to gain, sustain, and grow its customer base and competitive advantages (Nábrádi et al., 2018).

For many corporations, profit rather than vision or mission is the primary motivator, but profit alone is not enough to motivate people. Profit is perceived negatively by some stakeholders of some firms. For example, employees may see profit as something that they earn and management uses and even gives away to shareholders. Other research indicates focusing on a customer perspective is advantageous (David et al., 2016) Although this perception is disturbing to management, it clearly indicates that both profit and vision/ mission are needed to motivate a workforce effectively (David et al., 2014).

\section{Vision Statements}

It is especially important for managers and executives in any firm to agree on the basic vision the organization strives to achieve in the long term. A vision statement should answer the basic question, "What do we want to become?" A clear vision provides the foundation for developing a comprehensive mission statement. Many organizations have both a vision and mission statement, but the vision statement should be established first and foremost.

Many organizations today develop a vision statement that answers the question "What do we want to become?" Developing a vision statement is often considered the first step in strategic planning, preceding even development of a mission statement. Many vision statements are a single sentence. However, a vision statement should reveal the type of business the firm engages. For example, a vision that says, "to become the best retailing firm in the United States," is too broad because that firm could be selling anything from apples (A) to zebras (Z). Although typically a single sentence, vision statements need to do more than identify the product or service a firm offers; 
vision statements should be written from a customer perspective. Ideally every organization wants its employees and customers to align their actions with the firm's vision. To fulfil this need, an excellent vision statement describes a desired future state. Being futuristic enables vision statements to be used to facilitate organizational change. The statement needs to be doable but challenging.

Increasingly today firms are developing vision statements that exhibit the following five characteristics; these five attributes can be used as guidelines for writing or evaluating vision statements. Any vision statement that scores a 5 out of 5 on these characteristics is exemplary. Let's call this vision assessment technique "The 5 out of 5 Test." When employees and managers together shape or fashion a vision statement of a firm, the resultant document can reflect the personal visions that managers and employees have in their hearts and minds about their own futures. Shared vision creates a commonality of interests that can lift workers out of the monotony of daily work and put them into a new world of opportunity, challenge, and belongingness. The motivation, dedication, and commitment associated with shared vision is an immense potential benefit for any firm or organization (David, David, David, 2020, p. 47).

1. Clear: reveals type of industry and what firm strives to become

2. Futuristic: reveals what the firm strives to become or accomplish within 5 years

3. Concise: one sentence in length

4. Unique: reveals the firm's competitive advantage

5. Inspiring: motivates to readers to support the firm

There is no one best vision statement for a particular company in a given industry, but the 5 out of 5 test can be used to both develop and evaluate vision statements. Three hypothetical, exemplary vision statements that meet the 5 out of 5 test are provided below:

Dr Pepper Snapple: to be the best beverage business globally; our brands are synonymous with refreshment, fun, and flavour today and tomorrow.

IBM: to be the world's most successful information technology company focused on helping customers apply technology to solve their problems now and in the future.

Hilton Worldwide: to fill the Earth with the light and warmth of hospitality by delivering exceptional experiences-every hotel and guest for all time

Source: David, Fred R., David, Forest R., and David, Meredith E. 2020. Strategic Management Concepts and Cases - A Competitive Advantage Approach, 17th Edition. Pearson Education: Hoboken, N.J., p. 46.

\section{Mission Statements}

A mission statement is an "enduring statement of purpose that distinguishes one business from other similar firms. A mission statement identifies the scope of a firm's operations in product and market terms." It addresses the basic question that faces all strategists: "What is our business?" Developing a mission statement necessitates strategists pondering the nature and scope of present operations and to assess the potential attractiveness of future markets and activities. A mission statement functions as a constant reminder to its employees of why the organization exists and what the founders envisioned when they put their money and viability at risk to breathe life into their dreams.

A mission statement is sometimes called a creed statement, a statement of purpose, a statement of philosophy, a statement of beliefs, a statement of business principles, or a statement "defining our business. All organizations have a reason for existence, even if strategists have not consciously transformed this reason into writing. Strategists must not spend most of every day on administrative and tactical concerns; nor should they rush quickly to establish objectives and implement strategies before development of a vision and mission statement. Undue haste is so widespread that many corporations, organizations, and small businesses globally have not yet developed a formal vision or mission statement.

A mission statement needs to be broad in scope for at least two major reasons. First, a quality mission statement allows for the development of a range of feasible alternative objectives and strategies without curtailing management creativity. An overly general statement that does not exclude any strategy alternatives could be dysfunctional. Apple's mission statement, for example, should not open the possibility for diversification into nursing homesor Ford Motor Company's into building airplanes. Additionally, a mission statement needs to be broad to reconcile differences effectively among, and appeal to, an organization's diverse stakeholders, the individuals and groups of individuals who have a special stake or claim on the company. In essence, numbers should not be included in a mission statement.

An effective mission statement should comprise less than one hundred words. The statement should arouse positive thoughts about an organization; it should be inspiring and motivate readers to action. A mission statement should be enduring, but subject to be changed at any time depending on changes anywhere in the integrative model of strategic management. An effective mission statement generates the impression that a firm is on the right track and worthy of investment from all stakeholders. A mission statement should include nine components (customers, products or services, markets, technology, concern for survival/ growth/profits, philosophy, distinctive competence, concern for public image, concern for employees).

Well-managed companies today develop and utilize mission statements that include the following ten characteristics to help insure the firm has an excellent foundation strategic planning: 
1. Broad in scope; does not include monetary amounts, numbers, percentages, ratios, or objectives

2. Concise; fewer than one hundred words in length

\section{Inspiring}

4. Identifies the utility of a firm's products

5. Reveals that the firm is socially responsible

6. Reveals that the firm is environmentally responsible

7. Includes nine components: customers, products or services, markets, technology, concern for survival/growth/ profits, philosophy, distinctive competence, concern for public image, concern for employees

8. Reconciliatory; resolves divergent views among stakeholders

9. Enduring but never cast in stone

10. Attracts customers; is written from a customer perspective

Source: David, Fred R., David, Forest R., and David, Meredith E. 2020. Strategic Management Concepts and Cases - A Competitive Advantage Approach, 17th Edition. Pearson Education: Hoboken, N.J., p. 49.

\section{Trend 2: perform swot analysis using aqcd factors}

SWOT analysis entails the discovery, utilization, and matching of key external and internal factors (Weihrich, 1982). External opportunities and threats refer to economic, social, cultural, demographic, environmental, political, legal, governmental, technological, and competitive trends and events that could substantially benefit or harm an organization in the future. Opportunities and threats are largely beyond the control of a single organization, thus, the word external. In contrast, internal strengths and weaknesses are an organization's controllable activities that are performed especially well or poorly. Internal factors arise in the activities of management, marketing, finance/accounting, production, and information systems of a business. Identifying and evaluating organizational strengths and weaknesses in the functional areas of a business is an essential strategicmanagement activity (Madai et al., 2019). Organizations strive to pursue strategies that capitalize on internal strengths and improve internal weaknesses.

SWOT analysis enables managers develop four types of strategies: SO (strengths-opportunities) strategies, WO (weaknesses-opportunities) strategies, ST (strengths-threats) strategies, and WT (weaknesses-threats) strategies. Matching key external and internal factors is a cornerstone activity in strategic planning. Thousands of organizations and companies annually perform SWOT analysis. However, most of those entities incorporate way too much vagueness in the process. Vagueness is disastrous in strategic planning (George \& MacMillan, 1985; Love, Priem, \& Lumpkin, 2002), thus providing impetus for this paper. Underlying external and internal factors that comprise SWOT analysis need to be specific in order to provide an adequate foundation for the generation of strategies (David, David, \& David, 2017). More recent researchers (Mohamed, et al., 2018) have expanded the SWOT literature by introducing more sophisticated pairwise comparisons for selection strategies, to remove bias and introduce a new weighting system. The need for specificity is where AQCD (actionable, quantitative, comparative, and divisional) comes into play. SWOT analysis is arguably the most widely used strategic planning tool in the world, and AQCD factors are mandatory for its success.

This paper reveals how and why the key to effective SWOT analysis is the inclusion of external and internal factors that meet AQCD criteria. Specifically, each external and internal factor included in a SWOT analysis needs to be stated in AQCD terms to the extent possible, in order to minimize misinterpretation and to pave the way for the generation of strategies that are sufficiently specific, enabling the assignment of costs to those actions. The need for specificity is too commonly neglected in doing strategic planning (T. Z . Kovács, \& A. Nábrádi, 2019).

\section{The aqcd test}

A recent journal article reveals that all external and internal SWOT factors need to meet AQCD criteria to the extent possible (David, Creek, \& David, 2020). The purpose of external and internal assessments is to develop a finite list of opportunities that could benefit a firm, threats that should be avoided or mitigated, strengths that need to be capitalized on, and weaknesses that need to be improved upon (Capps III \& Glissmeyer, 2012). As the term finite suggests, the external and internal assessments do not result in an exhaustive list of factors that could influence the business. For this reason, each SWOT factor should be specific and useful, which the AQCD test aims to assure. Normally ten opportunities, ten threats, ten strengths, and ten weaknesses comprise the foundational information in a SWOT analysis (Kearns, 1992).

\section{Actionable}

In a SWOT analysis, the term "actionable" refers to the need for each external and internal factor to be meaningful and helpful in ultimately deciding what actions or strategies a firm should consider pursuing. When actionable, firms are able to respond either offensively or defensively to the factors by formulating strategies that capitalize on external opportunities, minimize the impact of potential threats, take advantage of strengths, and/or improve upon weaknesses. Actionable factors should be specific and within the control of management (Coman \& Ronen, 2009). For example, a factor such as "the firm's current ratio is 2.25 " is not actionable because it gives no insight on what to do about the issue.

\section{Quantitative}

The importance of objective strategic planning has long been advocated in management literature (e.g., David, 1986; Tavana and Banerjee, 1995). In a SWOT analysis, the 
term "quantitative" refers to the need for each external and internal factor to include percentages, ratios, currencies, and numbers to the extent possible. Quantification is essential so strategists can assess the magnitude of opportunities and threats and take appropriate actions. For example, rather than saying "Marketing is moving rapidly to social media," strategists need to conduct research and find, for example, that "spending on online advertisements globally is rising 13 percent annually and represents about 48 percent of total advertising spending in the USA." A key reason why strategies should be formulated and implemented based on specific factual information to the extent possible is the high stakes associated with strategic planning.

\section{Comparative}

In a SWOT analysis, the term "comparative" refers to the need for external and internal factors to reveal changes over time or versus rival firms or compared to industry averages. Otherwise it is difficult to put any fact or number in perspective. Thus, factors to be included in a SWOT analysis should be garnered in comparative terms, so managers can more effectively use the information in the matching process to generate feasible alternative strategies. Comparative factors can help to identify distinctive competencies (Kumar, Massie, \& Dumonceaux, 2006) or reveal the most appropriate locations to source and market products (Kogut, 1986). Vagueness is harmful in factor generation because millions or even billions of dollars could ultimately hinge on the strategic decisions that the factors provide a basis for making.

\section{Divisional}

In a SWOT analysis, the term "divisional" relates to the firm's profit centers that could be for example by various products and/or regions. Monitoring divisional factors allow inferences to be drawn regarding what products and regions are doing well or poorly. This distinction is especially important since more and more firms are shifting strategic management responsibilities from the corporate level to the divisional level (Grant, 2003). Arguably the most important strategic decision that faces companies and organizations annually is how best to allocate resources across its segments (divisions), regions, or products (David, et al., 2020). Therefore, to the extent possible, couching external and internal factors in divisional terms, rather than whole firm terms, is helpful and actually essential in deciding how to allocate scarce resources across divisions/segments.

\section{Trend 3: utilize varied sources to obtain aqcd information}

Another key trend being recently incorporated by organizations in more effectively doing strategic planning is to utilize varied sources to obtain AQCD information. A wealth of strategic information is available to organizations from both published and unpublished sources. Unpublished sources include customer surveys, market research, speeches at professional and shareholders' meetings, television programs, interviews, and conversations with stakeholders. Published sources of strategic information include periodicals, journals, reports, government documents, abstracts, books, directories, newspapers, and manuals. There are many excellent websites for gathering strategic information, but six outstanding sites that firms are increasingly utilizing to obtain AQCD information are as follows:

1. http://finance.yahoo.com

2. www.hoovers.com

3. www.morningstar.com

4. www,mergentonline.com

5. http://globaledge.msu.edu/industries/

6. Corporate website of companies

The fifth website listed above is operated by Michigan State University and provides industry profiles that are an excellent source for information, news, events, and statistical data for any industry. In addition, the following databases are increasingly being utilized in developing, determining, and prioritizing $\mathrm{AQCD}$ oriented external and internal factors for inclusion in SWOT and QSPM (discussed next) analyses:

- IBISWorld-Provides online USA Industry Reports (NAICS), U.S. Industry iExpert Summaries, and U.S. Business Environment Profiles. A global version of IBIS is also available.

- Lexis-Nexis Academic-Provides online access to newspaper articles (including New York Times and Washington Post) and business information (including SEC filings).

- Lexis-Nexis Company Dossier-Provides online access to extensive, current data on 13 million companies. It collects and compiles information into excellent documents.

- Mergent Online-Provides online access to Mergent's Manuals, which include trend, descriptive, and statistical information on hundreds of public companies and industries. Unconsolidated company income statements and balance sheets are provided.

- PrivCo-Provides information on privately held companies, including private financials and revenues; private $M \& A$ deals and deal multiples, private firm valuations, $\mathrm{VC}$ funding, private equity deal history; and private and family ownership data.

- Regional Business News-Provides comprehensive full-text coverage for regional business publications; incorporates coverage of more than 80 regional business publications covering all metropolitan and rural areas within the United States.

- Standard \& Poor's NetAdvantage-Provides online access to Standard \& Poor's (S\&P) Industry Surveys, stock reports, corporation records, The Outlook, mutual fund reports, and more. Locate the "Company" tab at the top of the page or the "Simple Search" option located on the right side of the page. Use the "Company Profile option.

- Value Line Investment Survey-Provides excellent on- 
line information and advice on approximately 1,700 stocks, more than 90 industries, the stock market, and the economy. Company income statements and balance sheets are provided.

- U.S. Securities and Exchange Commission-Provides the Form $10 \mathrm{~K}$ for publicly held companies in the United States. Use the search box at the top of the page or look under the Filings" tab along the top of the page.

- Company Annual Reports On-Line (CAROL)-Provides direct links to publicly held companies financial statements in both Europe and the United States.

Source: David, Fred R., David, Forest R., and David, Meredith E. 2020. Strategic Management Concepts and Cases - A Competitive Advantage Approach, 17th Edition. Pearson Education: Hoboken, N.J., p. 78.

\section{Trend 4: utilize qspm analysis to determine the relative attractiveness of strategies}

Because no organization has unlimited resources, top managers must decide which alternative strategies will benefit the firm most. Strategy-formulation decisions commit an organization to specific products, markets, resources, and technologies over an extended period of time. Strategies determine long-term competitive advantages. For better or worse, strategic decisions have major multifunctional consequences and enduring effects on an organization. Top managers have the best perspective to understand fully the ramifications of strategy-formulation decisions; they have the authority to commit the resources necessary for implementation.

Other than ranking strategies to determine their respective relative attractiveness, organizations are increasingly using QSPM (Quantitative Strategic Planning Matrix) analysis (David, 1986; David, David, \& David, 2017). The QSPM allows strategists to evaluate alternative strategies objectively, based on previously identified external and internal key success factors. Like other strategy-formulation analytical tools, the QSPM requires the assignment of ratings (called attractiveness scores), but making "small" rating decisions enables strategists to make effective "big" decisions, such as which country to spend a billion dollars in to sell a product. Conceptually, QSPM analysis is used to determine the relative attractiveness of various strategies based on the extent that key external and internal factors are capitalized on or improved David, et al., (2016). The relative attractiveness of each strategy is computed by determining the cumulative impact of each external and internal factor. Any number of strategies can be included in the QSPM.

The basic format of the QSPM is illustrated in Table 1. Note that the left column of a QSPM consists of key external and internal factors (from Stage 1), and the top row consists of feasible alternative strategies (from Stage 2). Specifically, the left column of a QSPM consists of information obtained directly from a SWOT analysis respective external and internal factors. In a QSPM, strategies should be stated in specific terms, such as "Open 275 new stores in Indonesia," rather than "Expand globally" or "Open new stores in Africa."
Specificity is vital because ultimately a dollar value must be established for each recommended strategy; it would be impossible to establish a dollar value for "expand globally." If you cannot reasonably assign a dollar value to a QSPM (or SWOT) strategy, then the strategy is too vague. Companies today have come to realize that vagueness is disastrous in strategic planning.

Table 1 - The QSPM Basic Format

\begin{tabular}{|c|c|c|c|c|c|c|c|}
\hline \multicolumn{8}{|c|}{ Alternative strategies } \\
\hline & \multirow[t]{2}{*}{ Weight } & \multicolumn{2}{|c|}{ Strategy 1} & \multicolumn{2}{|c|}{ Strategy 2} & \multicolumn{2}{|c|}{ Strategy 3} \\
\hline & & AS & TAS & AS & TAS & AS & TAS \\
\hline \multicolumn{8}{|l|}{ Key external factors } \\
\hline Economy & 0,25 & 1 &, 25 & 3 & ,75 & 2 &, 50 \\
\hline $\begin{array}{l}\text { Political/legal/ } \\
\text { governmental }\end{array}$ & 0,30 & - & & - & & - & \\
\hline $\begin{array}{l}\text { Social/cultural/demo- } \\
\text { graphic/environmental }\end{array}$ & 0,10 & 1 &, 10 & 2 &, 20 & 3 &, 30 \\
\hline Technological & 0,20 & - & & - & & - & \\
\hline Competitive & 0,15 & 2 &, 30 & 1 &, 15 & 3 &, 45 \\
\hline External total & 1,00 & - & & & & & \\
\hline \multicolumn{8}{|l|}{ Key internal factors } \\
\hline Management & 0,15 & 3 & ,45 & 2 &, 30 & 1 &, 15 \\
\hline Marketing & 0,25 & - & & - & & - & \\
\hline Finance/accounting & 0,20 & - & & - & & - & \\
\hline Production/operations & 0,15 & 3 & ,45 & 1 &, 15 & 2 &, 30 \\
\hline $\begin{array}{l}\text { Research and } \\
\text { development }\end{array}$ & 0,20 & 2 & ,40 & 1 & ,20 & 3 & ,60 \\
\hline $\begin{array}{l}\text { Management information } \\
\text { systems }\end{array}$ & 0,05 & 1 &, 05 & 2 &, 10 & 3 &, 15 \\
\hline Internal total & 1,00 & & & & & & \\
\hline $\begin{array}{l}\text { Sum total attractiveness } \\
\text { scores }\end{array}$ & 2,00 & 13 & 2,00 & 12 & 1,85 & 17 & 2,45 \\
\hline
\end{tabular}

Source: Meredith E. David, Fred R. David \& Forest R. David (2016)

The components of the QSPM include: strategic alternatives, key factors, weights, attractiveness scores (AS), total attractiveness scores (TAS), and the sum total attractiveness score. The three new terms just introduced-(1) attractiveness score, (2) total attractiveness score, and (3) the sum total attractiveness score-are defined and explained as the six steps required to develop a QSPM are discussed below (David, David, \& David, 2020, p. 183-184):

\section{Step 1}

Make a list of the firm's key external opportunities and threats and internal strengths and weaknesses in the left column of the QSPM. This information should be taken directly from a SWOT analysis.

\section{Step 2}

Assign weights to each key external and internal factor. These weights are identical to those in the EFE (External 
Factor Evaluation) Matrix and IFE (Internal Factor Evaluation) Matrix. The weights are presented in a straight column just to the right of the external and internal factors.

\section{Step 3}

Examine the Stage 2 matching matrices, and identify alternative strategies that the organization should consider implementing. Record these strategies in the top row of the QSPM.

\section{Step 4}

Determine the Attractiveness Scores (AS), defined as numerical values that indicate the relative attractiveness of each strategy considering a single external or internal factor. Attractiveness Scores (AS) are determined by examining each key external or internal factor, one at a time, and asking the question, "Does this factor affect the choice of strategies being made?" If the answer to this question is yes, then the strategies should be compared relative to that key factor. Specifically, AS should be assigned to each strategy to indicate the relative attractiveness of one strategy over others, considering the particular factor. The range for AS is $1=$ not attractive, 2 $=$ somewhat attractive, $3=$ reasonably attractive, and $4=$ highly attractive. By "attractive," we mean the extent that one strategy, compared to others, enables the firm to either capitalize on the strength, improve on the weakness, exploit the opportunity, or avoid the threat. Work row by row in developing a QSPM. If the answer to the previous question is no, indicating the respective key factor has no effect on the specific choice being made, then do not assign AS to the strategies in that set. Use a dash (or 0 if using the template) to indicate that the key factor does not affect the choice being made. Note: If you assign an AS score to one strategy, then assign an AS score(s) to the other-in other words, if one strategy receives a dash (or 0 ) - then all others must receive a dash (or 0) in a given row.

\section{Step 5}

Compute the Total Attractiveness Scores (TAS). TAS are defined as the product of multiplying the weights (Step 2) by the AS (Step 4) in each row. The TAS indicate the relative attractiveness of each alternative strategy, considering only the impact of the adjacent external or internal critical success factor. The higher the TAS, the more attractive the strategic alternative (considering only the adjacent critical success factor).

\section{Step 6}

Compute the Sum Total Attractiveness Score. Add TAS in each strategy column of the QSPM. The Sum Total Attractiveness Scores (STAS) reveal which strategy is most attractive in each set of alternatives. Higher scores indicate more attractive strategies, considering all the relevant external and internal factors that could affect the strategic decisions. The magnitude of the difference between the STAS in a given set of strategic alternatives indicates the relative desirability of one strategy over another.

QSPM analysis can be used to make decisions in a variety of business types ranging from small businesses to large multinational corporations, not-for-profits and governments. With respect to using QSPM analysis in a rapidly changing world, the technique can be immensely helpful. Take for example the new BMW plant on schedule to be built in Debrecen, Hungary. BMW could have used QSPM analysis to weight and rank various options on the plant location and ultimately BMW decided on Debrecen for the new plant location. Major strategic decisions require increased research and objective decision-making; it is our view that QSPM analysis is especially effective and useful when the data flowing from the SWOT is well researched and meets AQCD standards. A rapidly changing world and increased need for agility necessitates well thought out and constructed strategic long term strategies; QSPM analysis can aid immensely in making excellent long term strategic decisions in a turbulent business environment such as we experience today.

QSPM can also be effectively used for more tactical mid range strategies. For example, BMW deciding on increasing SUV production by 5 percent or increasing compact electric car production by 5 percent could also be determined through QSPM analysis. An example such as this would address a more agile business environment where consumer preferences change more frequently than historically. This latter example is not as strategic in nature as where to locate a new facility, as more tactical strategies such as these can be changed the next year more easily than relocating a manufacturing facility. In many respects, having a detailed strategic planning process and using techniques similar to the QSPM are more important now than ever since there is far less forgiveness for strategic mistakes due to increased agility of rival firms and everchanging consumer preferences and habits.

\section{Trend 5: use excel-based software to facilitate the strategic planning process}

Another emerging trend or tool being utilized by companies to more effectively do strategic planning is incorporation of excel-based software to facilitate the process. Specifically, the software provided at the www.strategyclub.com website is increasingly being used by companies to facilitate development of appropriate planning matrices and more. Given below are twelve reasons that companies today are using the excel-based strategic planning template at www.strategyclub.com (David, David, \& David, 2020, p. 23)

1. To save time in preparing a strategic-management case analysis; enables user to focus on the "thinking rather than the mechanics" of developing matrices and performing analyses.

2. To follow the correct process in formulating and implementing strategies.

3. To avoid mistakes in math calculations, plotting points, and drawing graphs.

4. To develop professional-looking charts, graphs, and matrices.

5. To develop existing and projected financial ratios.

6. To correctly place firms in BCG and IE portfolio matrices. 
7. To examine many different scenarios for using debt versus stock to raise needed capital, using EPS-EBIT analysis.

8. To vary weights and ratings in matrices and to see the resultant impact on total weighted scores.

9. To more easily share information with team members and colleagues.

10. To more easily develop projected financial statements to reveal the expected impact of various strategies.

11. To develop skills with perceptual mapping or product positioning.

12. To gain experience using actual corporate strategic planning software; many business jobs require proficiency in Excel, which students gain in using the template. $</ \mathrm{TBL}>$

\section{CONCLUSION}

Strategic management enables a business or organization to be proactive rather than reactive in shaping its own future; it allows an organization to initiate and influence (rather than just respond to) activities, and thus, to exert control over its own destiny. Small business owners, chief executive officers, presidents, and managers of many for-profit and nonprofit organizations have recognized the importance of doing strategic planning effectively - and they are increasingly using the five tools and techniques described in this paper to be successful in this endeavour. To gain and sustain competitive advantages, firms must create and nurture a clear vision and mission, and then systematically perform SWOT and QSPM analyses utilizing AQCD oriented factors.

Consistent business success rarely happens by luck or chance; it most often results from careful strategic planning followed by diligent, intelligent, hard work. If the process were easy, every business would be successful. Scanning appropriate external and internal sources of information, as described in this paper, to identify and prioritize key AQCD oriented external and internal factors is critically important - rather than just haphazardly deciding upon vague, useless, nebulous, external and internal factors. Consistent success requires that strategists gather and assimilate relevant data, make tough trade-off decisions among various options that would benefit the firm, motivate and reward employees, and continually adapt to change. Additionally, using modern strategic planning software to facilitate staying on track in working through the planning process is increasingly being practiced.

Most persons or organizations realize that developing an excellent strategic plan can be the difference between organizational success and failure. Hopefully this paper provides guidance to managers of all kinds of organizations as they strive to continually improve "how they do strategic planning" to help gain and sustain competitive advantage.

\section{REFERENCES}

Basset, Mohamed Abdel; Mohamed, Mai; Sangaiah, Arun Kumar; Jain, Vipul. Benchmarking: An International Journal. 2018, Vol. 25 Issue 7, p2546-2564. 19p.
Bryson, John M.; Edwards, Lauren Hamilton; Van Slyke, David M. Public Management Review. Mar2018, Vol. 20 Issue 3, p317-339. 23p

Capps III, C. J., \& Glissmeyer, M. D. (2012). Extending the competitive profile matrix using internal factor evaluation and external factor evaluation matrix concepts. Journal of Applied Business Research, 28(5): 1059.

Coman, A., \& Ronen, B. (2009). Focused SWOT: diagnosing critical strengths and weaknesses. International Journal of Production Research, 47(20), 5677-5689.

David, Fred R., Creek, Steven, \& David, F.R. (2020). What is the key to effective SWOT analysis? Including AQCD Factors. SAM Advanced Management Journal, 2020, 84(1): 25-36.

David, Fred R., David, Forest R., \& David, Meredith E. (2020). Strategic Management Concepts and Cases - A Competitive Advantage Approach, 17th Edition. Pearson Education: Hoboken, N.J.

David, F. R. (1986). The strategic planning matrix-A quantitative approach. Long Range Planning, 19(5): 102-107.

David, M. E., David, F. R., \& David, F. R. (2017). The Quantitative Strategic Planning Matrix (QSPM): A new marketing tool. Journal of Strategic Marketing, 25(4): 342-352.

David, Fred R., David, F.R.. \& David, M.E.. (2016). Benefits, characteristics, components, and examples of customer-oriented mission statements. International Journal of Business, Marketing, and Decision Sciences (IJBMDS), 9(1): 19-32.

David, Meredith E, David, Forest R, \& David, Fred R. (2014). Mission statement theory and practice: A content analysis and new direction. International Journal of Business, Marketing, and Decision Sciences (IJBMDS), 7(1): 95-109.

Meredith E. David, Fred R. David \& Forest R. David (2016): The quantitative strategic planning matrix: a new marketing tool, Journal of Strategic Marketing http://dx.doi.org/10.1080/0 965254X.2016.1148763

George, R., \& MacMillan, I. C. (1985). Corporate venturing: Venture management challenges. Journal of Business Strategy, 6(2): 85-91.

Grant, R. M. (2003). Strategic planning in a turbulent environment: Evidence from the oil majors. Strategic Management Journal, 24(6): 491-517.

H. Madai, B. Bittner, A. Sz. Nagy, \& A. Nábrádi (2019). Methodological approach to the practice of strategy planning in particular the internal environmental analysis. Proceedings of the 9th International Conference on Management. "People, Planet and Profit: Sustainable business and society" 148-153.p. DOI: 10.17626/dBEM.ICoM.P02.2019.p072 
Kearns, K. P. (1992). From comparative advantage to damage control: Clarifying strategic issues using SWOT analysis. Nonprofit Management and Leadership, 3(1): 3-22.

Kogut, B. (1985). Designing global strategies: Comparative and competitive value-added chains. Sloan Management Review, 26(4): 15 .

Love, L. G., Priem, R. L., \& Lumpkin, G. T. (2002). Explicitly articulated strategy and firm performance under alternative levels of centralization. Journal of Management, 28(5), 611-627.

Nábrádi A. (ed), Bittner B., Madai H., Nagy, \& A., Nábrádi A. (2018). A stratégiai tervezés gyakorlata (The Practice of Strategic Planning). Debreceni Egyetem, Debrecen, p. 7-158. ISBN 978-963-490-053-5.

Sameer Kumar, Cindy Massie, Michelle D. Dumonceaux (2006). Comparative innovative business strategies of major players in cosmetic industry. Industrial Management \& Data Systems 106(3):285-306. DOI: 10.1108/02635570610653461.

Tavana, M., \& Banerjee, S. (1995). Strategic assessment model (SAM): A multiple criteria decision support system for evaluation of strategic alternatives. Decision Sciences, 26(1): 119-143.

Tünde Zita Kovács \& András Nábrádi (2019). Categories of sharing economy and collaborative consumption. Book of Abstracts of International Conference on Economics of Decoupling (ICED). 2 - 3 December 2019, Zagreb, Croatia. University of Zagreb. ISSN: 2706-4433.

Weihrich, H. (1982). The TOWS Matrix: A tool for situational analysis. Long Range Planning, 15(2): 54-66. 